\title{
THE AMPHITHEATRE OF CARNUNTUM - TOWARDS A COMPLETE 3D MODEL USING AIRBORNE STRUCTURE FROM MOTION AND DENSE IMAGE MATCHING
}

\author{
G. Verhoeven, R. Docter
}

\section{HARD- AND SOFTWARE IMPROVEMENTS IN LOW-ALTITUDE AERIAL PHOTOGRAPHY}

Archaeological practice has always faced huge challenges in terms of fast and accurate three-dimensional data recording, whether during excavations, artefact analysis or the mapping of archaeological remains throughout the landscape. To enable the latter, aerial photography from a low-flying aircraft has been the archaeology workhorse, since it is one of the most effective methods for site discovery and documentation. However, since the beginning of aerial photography, researchers have also been using all kinds of unmanned devices (from pigeons, kites, poles, and balloons to rockets and satellites) to take still cameras aloft and remotely gather aerial imagery (Verhoeven, 2009). To date, many of these unmanned devices are still used, enabling so-called Low-Altitude Aerial Photography (LAAP). Besides these more traditional camera platforms, radio-controlled multiple-rotor platforms (multicopters) have recently opened a completely new approach to LAAP. The overwhelming variety of brands and types (tricopters, quadcopters, hexacopters, octocopters etc.), together with the wide variety of navigation options (e.g. altitude and position hold, waypoint flight) and camera mounts indicate that these platforms are here to stay for a while. Given the multitude of still camera types and the image quality they are currently capable of, an endless combination of lowand high-cost LAAP solutions is available, enabling the acquisition of aerial photographs with a spatial and temporal resolution impossible to achieve with the manned aircraft solutions.

Next to these significant hardware developments, research in computer vision and photogrammetry lead to advanced automated procedures in image orientation and image matching. When combined with the improvements in the power of computer processors and graphical cards, these software approaches now make it possible to generate 3D geometry from image data in a rather fast and straightforward way. To show the potential of

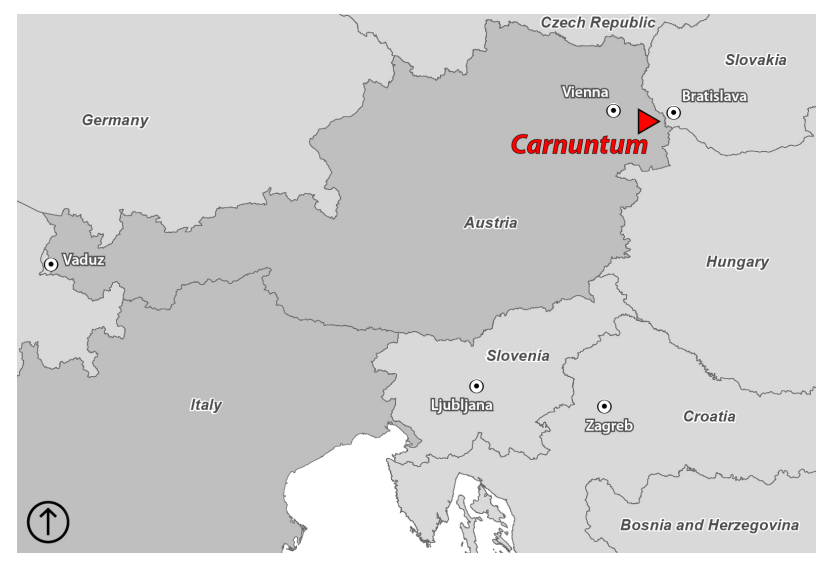

Figure 1: The location of Roman Carnuntum. integrating all aforementioned hard- and software developments, a 3D model and orthophotograph were created from the $2^{\text {nd }}$ century AD amphitheatre of Carnuntum.

\section{IMAGING CARNUNTUM'S CIVIL AMPHITHEATRE}

The Roman town of Carnuntum (currently Petronell-Carnuntum in Austria, located $40 \mathrm{~km}$ southeast of Vienna on the southern bank of the Danube river - Figure 1), was home to some 50,000 inhabitants and consisted of both a Roman legionary camp with associated civilian settlement (canabae) and a civil town.

The photographed amphitheatre is located outside the gates of the civil town. The aerial imagery used in this reconstruction was acquired with a radio-controlled Microdrone md4-1000 quadrocopter (Figure 2). During the flight, photographs were taken at specific spots in such a way that they had a sufficient amount of overlap with the neighbouring photographs.

\section{TOWARDS A 3D MODEL}

After sorting out the sharpest images, a 3D model and orthophoto were calculated using this new approach. In a first phase, the process uses a technique called Structure from Motion (SfM; Ullman, 1979). In essence, SfM allows the reconstruction of three-dimensional scene geometry and the exact position of the cameras during image acquisition from a sequence of twodimensional imagery captured by a camera moving around the scene (Szeliski, 2011; Figure 3A1). To do so, SfM relies on algorithms that detect feature points for each image (Figure 3A2) and subsequently tries to match those $2 \mathrm{D}$ points throughout the image series (Figure 3A3). Using these obtained point correspondences SfM computes the locations of those feature points

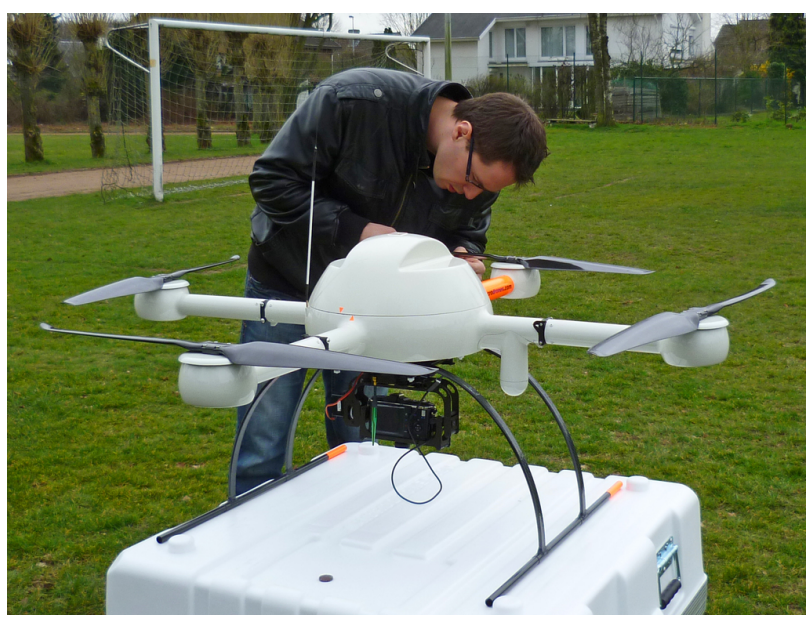

Figure 2: The Microdrone md4-1000 quadrocopter. 
and renders them as a sparse $3 \mathrm{D}$ point cloud that represents the structure of the scene in a local coordinate frame (Figure 3B). As $\mathrm{SfM}$ greatly depends on the accurate knowledge of camera positions, estimating the latter is one of the core components in the whole process (Hartley and Zisserman, 2003). More specifically, the complete projection geometry of all images is computed: the interior camera calibration parameters (focal length, the principal point location plus lens distortion coefficients), the position of the camera projection centre and six exterior orientation parameters defining the camera orientation at the moment of image acquisition (Robertson and Cipolla, 2009; Figure 3B). At this stage, the reconstruction is still expressed in a local coordinate framework and equivalent of the original scene up to a global scale and rotation factor. To transform the camera positions and point cloud into an absolute coordinate system, a Helmert similarity transformation, using at least three ground control points with known altitude values, is applied.

SfM has recently received a great deal of attention due to Bundler, Microsoft's Photosynth and Autodesk's Project Photofly (now called 123D Catch): three SfM implementations that are freely available on the Web. Commercial SfM solutions are also available, including as AgiSoft's PhotoScan or Pix4D's cloud processing software. Most of these software solutions also come with additional functionality to yield a dense representation of the scene's surface geometry using one or more multi-view stereo (MVS) algorithms. Because such dense MVS solutions operate on the pixel values instead of on the feature points (Seitz et al., 2006), this additional step enables the generation of detailed three-dimensional point clouds or triangular meshes (Figure 3C). When working with aerial images, the resulting model can be considered a digital surface model (DSM): a numerical representation of the topography and all its imposed structures such as trees and houses. As is known from conventional orthophoto generation, such a dense DSM is elementary when one wants to generate true orthophotos in which all objects with a certain height (such as houses, towers and trees) are also accurately positioned. Since all necessary information is available, a detailed and accurate orthophoto can now be produced (Figure 3D).

\section{SOME CONSIDERATIONS}

Although the presented algorithms function best when run on computers with multicore processors, a decent amount of RAM (minimum $8 \mathrm{~GB}$ ), a 64-bit operating system and a high-end graphical card, they offer an enormous advantage in that they can be used with archaeologists' usual oblique photographs. Apart from a sufficient number of sharp images covering the scene to be reconstructed and at least three GCPs to pin down the reconstruction, no other information is needed. Furthermore, only minimal technical knowledge and user interaction are required. However, it has to be stressed that it is not all roses here: the method is not applicable for an individual image, and the determination of the correct camera projection geometry can fail when dealing with blurred, noisy and badly exposed images or photographs that have a very dissimilar appearance (e.g. due to major underexposure or changing topographic terrain parameters). For a more elaborate overview and multiple examples of this 3D and orthophoto procedure applied on aerial archaeological imagery, consider Verhoeven et al. (2012a). Additionally, research by Doneus et al. (2011) proved how well this method holds up when compared with terrestrial laser scanning in an excavation context, while Verhoeven et al. (2012b) thor- oughly evaluated the positional accuracy of the generated orthophotographs. This type of quality control and documentation is essential in order to ensure the proper quality of the final products.

\section{ACKNOWLEDGEMENTS}

The Ludwig Boltzmann Institute for Archaeological Prospection and Virtual Archaeology (http://archpro.lbg.ac.at is based on an international cooperation of the Ludwig Boltzmann Gesellschaft (A), the University of Vienna (A), the Vienna University of Technology (A), the Austrian Central Institute for Meteorology and Geodynamic (A), the office of the provincial government of Lower Austria (A), Airborne Technologies GmbH (A), RGZM-RomaneGermanic Central Museum Mainz (D), RAÄ-Swedish National Heritage Board (S), IBM VISTAUniversity of Birmingham (GB) and NIKU-Norwegian Institute for Cultural Heritage Research (N). Furthermore, the authors acknowledge the Dioraphte Foundation in the Netherlands for the generous financial support that enabled them to use this Microdrone in this archaeological research.

\section{REFERENCES}

Doneus M, 2001. Precision mapping and interpretation of oblique aerial photographs. Archaeological Prospection 8: 13-27.

Doneus M, Verhoeven G, Fera M, Briese C, Kucera M, Neubauer W. 2011. From deposit to point cloud - A study of low-cost computer vision approaches for the straightforward documentation of archaeological excavations. In Proceedings of the XXIIIrd International CIPA Symposium, Prague, Czech Republic, September 12 - 16, 2011, Pavelka, K (ed.). CIPA Heritage Documentation: Prague.

HARTLEY R, ZISSERMAN A. 2003. Multiple view geometry in computer vision. $2^{\text {nd }}$ ed. Cambridge University Press: Cambridge.

RoBERTSON DP, CIPOLla R. 2009. Structure from Motion. In Practical image processing and computer vision, Varga M (Ed.). John Wiley and Sons Ltd: New York; sp.

Seitz SM, Curless B, Diebel J, Scharstein D, Szeliski R. 2006. A Comparison and Evaluation of Multi-View Stereo Reconstruction Algorithms. In 2006 IEEE Computer Society Conference on Computer Vision and Pattern Recognition, Volume 1 (CVPR'06). IEEE: Washington; 519-528.

SZELISKI R. 2011. Computer vision. Algorithms and applications. Springer, New York.

ULLMAN S. 1979. The interpretation of structure from motion. Proceedings of the Royal Society of London B 203: 405-426.

Verhoeven G. 2009. Providing an archaeological bird's-eye view. An overall picture of ground-based means to execute lowaltitude aerial photography (LAAP) in Archaeology. Archaeological Prospection 16: 233-249.

Verhoeven G, Doneus M, Briese C, Vermeulen F. 2012a. Mapping by matching - A computer vision-based approach to fast and accurate georeferencing of archaeological aerial photographs. Journal of Archaeological Science 39: 20602070.

Verhoeven G, Taelman D, Vermeulen F. 2012b. Computer vision-based orthophoto mapping of complex archaeological sites: the ancient quarry of Pitaranha (PortugalSpain). Archaeometry, published online - DOI: 10.1111/j.14754754.2012.00667.x 
The amphitheatre of Carnuntum - Towards a complete 3D model using airborne SfM and dense image matching
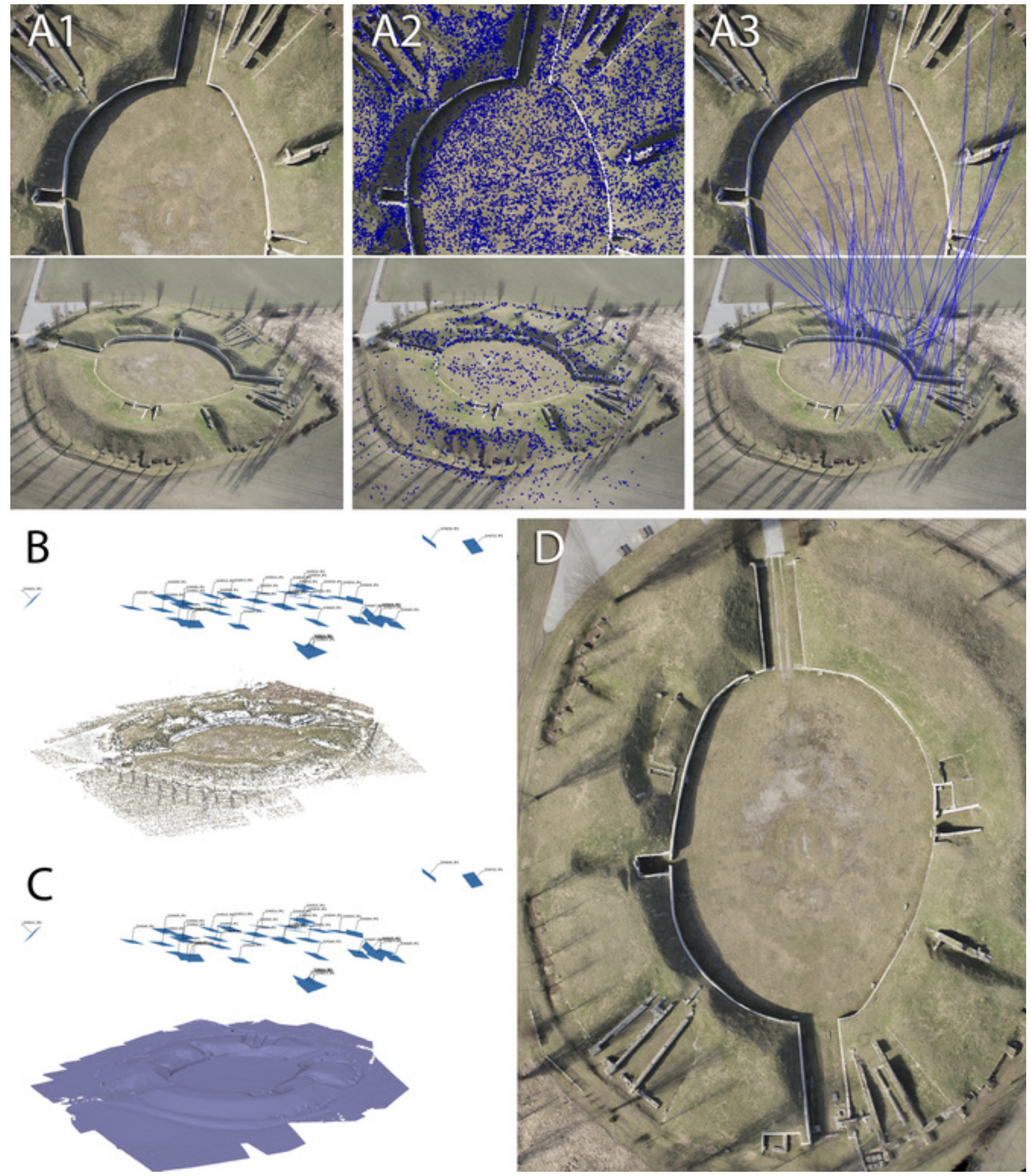

Figure 3: Structure from Motion and dense Multi-View Stereo steps for model generation. (details in section 3) 